\title{
Possible Impact of Overseas Study on Language Ability and Motivation to Study English
}

\author{
Setsuko Mori ${ }^{1} \&$ Peter Gobel $^{2}$ \\ ${ }^{1}$ Faculty of Law, Kindai University, Osaka, Japan \\ ${ }^{2}$ Faculty of Cultural Studies, Kyoto Sangyo University, Kyoto, Japan \\ Correspondence: Setsuko Mori, Faculty of Law, Kindai University, 3-4-1 Kowakae, Higashiosaka, Osaka, \\ 577-8502 Japan.
}

Received: July 31, 2021

Accepted: August 23, 2021

Online Published: August 27, 2021

doi: $10.5539 /$ elt.v14n9p32

URL: https://doi.org/10.5539/elt.v14n9p32

\begin{abstract}
The present study explored whether two semester overseas study programs had any impact on participants' language ability and motivation to study English. The language ability, L2 learning motivation and learning attitude of 65 Japanese university students participating in semester-long study abroad programs were measured pre departure and on their return. TOEIC listening and reading tests were used to measure students' linguistic gains, and possible changes to students' L2 motivation and attitudes were measured using a survey created specifically for the purpose of this study. Statistical analysis implied a significant effect from the two overseas programs on TOEIC scores and motivation and attitude, with motivational intensity prior to departure being a significant predictor of TOEIC gains. The findings underscore the idiosyncratic nature of studying abroad, and will be of use in designing and implementing post-overseas study programs.
\end{abstract}

Keywords: study abroad, motivational change, attitudinal change, linguistic improvement

\section{Introduction}

\subsection{Literature Review}

Studying abroad has been touted as one of the most efficient ways to learn a foreign language. In Japan, both students and institutions are aware of the value of study abroad programs, both for the language opportunities and the cultural exposure they provide. Although increased language proficiency is one of the most common results of studying abroad, cultural experience and the development of intercultural competence can be considered just as important. The Japan Student Services Organization (JASSO) reports that the number of Japanese students choosing to study abroad on formal Study Abroad (SA) programs has dramatically increased in recent years (JASSO, 2018). This is due in great part to the encouragement of the Japanese government (MEXT, 2011).

To date, most of the research on Japanese SA programs has concentrated on linguistic gains. In recent years more emphasis has been put on investigating changes in attitudes towards the target culture and learner beliefs about language learning and motivation. In recent years there have been a number of studies investigating how learning beliefs change as a result of overseas study. Verela (2017) performed a meta-analysis of 72 study-abroad investigations, finding that study abroad leads to positive cognitive, affective and behavioral gains. For the purposes of the present research, we will focus on two to specific affective categories: motivation and attitudes towards the target language and culture.

Some studies have investigated the role of studying abroad on intercultural sensitivity and attitudes towards the target language and culture. A number of studies have shown that SA experiences increased interest in international communities and intercultural sensitivity, particularly in the area of culture-centric attitudes. (Anderson, Lawton, Rexeisen, \& Hubbard, 2006; Yashima \& Zenuk-Nishide, 2008). SA experiences have also been found to have positive effects on attitudes towards the target culture and target population, which in turn affected socialization and linguistic gains (Paris, Nyaupane, \& Teye, 2014; Streitwieser \& Light, 2018; Watson \& Wolfel, 2015; Zaykovskaya, Rawal, \& De Costa, 2017). It has also been noted that the environment, program type, and predeparture orientations played significant roles in the development of intercultural competence (Hanada, 2019; Nowlan, 2020). 
The length of time spent abroad affects how motivation changes, with longer study abroad programs affecting both learner beliefs regarding learner autonomy and intrinsic motivation. A number of studies have reported how more time spent abroad changed student views of teacher's role and their own self efficacy (Amuzie \& Winke, 2009; Martin, 2020; Sasaki, 2011).

Context is another factor that needs to be taken into consideration. Both the design of the program, and student L2 proficiency may play a role in motivational changes (Miura, 2010; Yang \& Kim, 2011). As Miura's retrospective study of Japanese university students has shown, L2 learning motivation changes over time, being strongly influenced by context and L2 language proficiency. In addition, much of the motivation in that study was extrinsically rather than intrinsically or socially motivated. Program length can also be considered part of context, and shorter programs may have little effect on motivation (Martin, 2020; Nguyen et al., 2018).

Student views of themselves as L2 learners have been found to develop greatly during overseas study. One view is that L2 motivation is comprised of both an ideal L2 self and an ought-to L2 self, and the L2 learning experience itself (Dörnyei \& Ushioda, 2009). There is a causal relationship between the learning experience and motivation, with the individual learner's motivation mitigated through social interaction with others. A number of studies have noted changes in self-image (both ought-to L2 self and ideal L2 self), which also affected willingness to communicate, learning goals, and attitudes toward the target communities. It has been suggested that these changes contribute to long-term motivation and improvement in L2 proficiency (Barkhuizen, 2017; Fryer \& Roger, 2018; Hsieh, 2009; Moritani, Manning, \& Henneberry, 2016; Ueki \& Takeuchi, 2015; Yashima, Zenuk-Nishide, \& Shimizu, 2004).

The present study, influenced by these previous studies, builds on a pilot study conducted by one of the authors, by examining changes in linguistic proficiency, motivation and attitudes after participating in two similar SA programs.

\subsection{The Pilot Study}

Although the studies mentioned above highlight the effects of overseas study, there are few studies focusing on the connection between L2 proficiency and perceived motivational changes. To evaluate a semester-long study abroad program at her university Mori (2018) researched the connection between changes in L2 proficiency and motivational changes. Although the program had been active for over a decade, the only metric used for evaluation of program efficacy of the program was TOEIC listening and reading scores. Positive changes in affect were noted by the researcher, but never rigorously investigated. As a result, Mori sought to investigate specific changes to language skills, specific changes to motivation and attitude, and relationships between L2 proficiency changes and changes in motivation, attitude, and goal orientation.

Pre and post program TOEIC tests were administered to the 43 participants in the study as well as a questionnaire focusing on learner beliefs. The questionnaire was created using items from previously published and validated instruments (Dörnyei \& Ushioda, 2009; Gardner \& Lambert, 1972; Yashima, 1999; Yashima, 2009; Yashima, Zenuk-Nishide, \& Shimizu, 2004). The 27 items in the questionnaire focused on 6 areas: teacher's role in learning, self-efficacy, motivational intensity, desire to learn English, ideal L2 self, and ought-to L2 self.

Analysis of the data found that there were measurable gains in all four skills measured by the TOEIC, as well as positive gains in all but the variable of teacher's role in learning. Regarding correlations among the variables, listening and speaking scores were significantly correlated and gains in speaking skill correlated highly with motivational intensity. In addition, the variables of motivational intensity and desire to learn, desire to learn English and ought-to self, ought-to L2 self and ideal L2 self also showed strong correlations. Students viewed the program as allowing them to achieve an important goal of becoming a more international person.

\subsection{Objectives of the Present Study}

As Mori (2018) was a pilot study, focusing on just one program, it was felt that using a larger sample size and more than one setting (i.e., more than one program and one institution) would help to measure changes due more accurately to study abroad, and aid in generalizability of the findings. A second study was developed, using data from two separate semester-long study abroad programs.

Research questions for this study can be found below:

1) What facets of L2 learning motivation and attitude towards the foreign language change due to study abroad? 
2) Does a relationship exist between changes in students' motivation and attitude, and their linguistic gains?

3) Are motivational and attitudinal changes related in any capacity?

4) Is there a relevant correlation between students' pre-departure motivation and attitude and overall linguistic gains?

\section{Method}

\subsection{Participants}

Participants were two groups of students from two separate but academically comparable private universities. For sake of convenience, they are referred to as groups A and B. Both groups A and B participated in faculty-led semester-long study overseas programs. Group A was comprised of 43 sophomore students majoring in law who studied at the University of Calgary for a semester. Group B was comprised of 22 sophomore students majoring in cultural studies and studied at Thompson Rivers University for a semester. Selection process for both programs considered interview results, academic standing, and TOEFL or TOEIC scores. Interviews were conducted in both cases, with applicants being asked about reasons for applying for the respective program. Applicants in Group A were all members of a program for non-English majors (the English minor program). The majority of the applicants in Group B were part of special English communication program in the faculty which focused on increasing intercultural communication skills. The TOEIC mean scores prior to departure were 518 for group A and 495 for group B.

\subsection{Study Abroad Programs}

The two study abroad programs were both three months in length and implemented in Canada. The program that Group A participated in was offered by the Faculty of Law, specifically for students enrolled to study English as a minor to supplement a major in law. The study abroad program was created as an essential part of the English minor program, and participation SA was a requirement for program completion. The core of the SA program consisted of five hours of daily English classes, four days a week. Outside of this core, students participated in law-related extracurricular activities such as a visit to a court one day a week. Another requirement for completion of the program was to submit reports on Canadian current and social issues. The program also included a homestay component, where the students lived with English speaking families.

The program that Group B joined was offered in the Faculty of Cultural Studies and designed specifically for the English Communication Program in that faculty. Participation in the SA program is a graduation requirement for those students. The study abroad program includes English language classes (111 hours), a course on intercultural communication ( 45 hours), a course on Canadian studies (35 hours), classes to prepare the students for fieldwork (33 hours), and fieldwork. Fieldwork consisted of approximately 120 hours of working as volunteers in the community (retirement centers, daycare centers, and a local foodbank were common assignments). All students participated in homestays with English speaking families.

\subsection{Procedure}

The TOEIC Listening and Reading tests were used to measure both groups' English proficiency. Group A took the TOEIC one month prior to departure for Calgary and immediately upon their return. Group B also took a TOEIC Listening and Reading test prior to departure and after their return.

A motivational and attitudinal questionnaire was also administered to discover students' motivation and attitude prior to departure.

Upon the students' return to campus the questionnaire was readministered, though with slight modifications to reflect their experience abroad.

\subsection{Materials}

The questionnaire, consisting of 27 items, was adopted from previously validated survey instruments (Dörnyei \& Ushioda, 2009; Gardner \& Lambert, 1972; Yashima, 1999; Yashima, 2009; Yashima, Zenuk-Nishide, \& Shimizu, 2004) and divided into six subsections, namely Teacher's role, Self-efficacy, Motivational intensity, Desire to learn English, Ideal L2 self and Ought-to L2 self (See Mori, 2018 for details of the questionnaire). Internal consistency of the questionnaire, measured using Cronbach's alpha, was .77. 


\section{Results}

3.1 Research Question One: What Facets of L2 Learning Motivation and Attitude towards the Foreign Language Change due to Study Abroad

Table 1 displays the pre- and post-program descriptive statistics for both the overall TOEIC scores and the questionnaire. The participants exhibited positive gains on the TOEIC scores and two motivational and attitudinal variables, namely Self-efficacy and Motivational Intensity.

A series of independent samples $\mathrm{T}$ tests was conducted to determine if there were significant differences between pre- and post-program scores on the TOEIC and six motivational and attitudinal variables. The results implied a significant difference between pre- and post-program scores on the TOEIC, as well as self-efficacy and motivational intensity at $p<.00$.

Table 1. Mean Differences of Pre- and Post-Program TOEIC Scores and Questionnaire

\begin{tabular}{llllllll}
\hline & \multicolumn{2}{l}{ Pre-program } & \multicolumn{2}{l}{ Post-program } & \multirow{2}{*}{ Gain } & \multirow{2}{*}{$\begin{array}{l}\text { Sig. } \\
\text { (2-tailed) }\end{array}$} \\
& Mean & SD & Mean & SD & & & $\mathbf{0 . 0 0}$ \\
TOEIC & 510.57 & 98.88 & 558.62 & 94.06 & 48.05 & -5.53 & $\mathbf{0 . 0 0}$ \\
Teacher & 2.75 & 0.43 & 2.69 & 0.55 & -0.06 & 0.85 & 0.40 \\
Efficacy & 2.66 & 0.37 & 2.77 & 0.34 & 0.12 & -3.19 & $\mathbf{0 . 0 0}$ \\
Motivation & 3.10 & 0.36 & 3.21 & 0.38 & 0.11 & -2.67 & $\mathbf{0 . 0 1}$ \\
Desire & 3.16 & 0.45 & 3.20 & 0.46 & 0.04 & -0.52 & 0.60 \\
Ideal & 2.96 & 0.48 & 2.96 & 0.58 & -0.01 & 0.09 & 0.93 \\
Ought & 3.51 & 0.49 & 3.52 & 0.49 & 0.02 & -0.24 & 0.82 \\
\hline
\end{tabular}

3.2 Research Questions Two and Three: Does a Relationship Exist between Changes in Students'Motivation and Attitude, and Their Linguistic Gains? Are Motivational and Attitudinal Changes Related in Any Capacity

Correlations were calculated to uncover possible relationships among all variables concerning changes pre and post. As Table 2 shows, TOEIC score gains do not significantly correlate with any of the motivational and attitude changes.

Of the motivation and attitude variables, the strongest correlation at $\mathrm{p}<.01$ was found between changes on ought-to L2 self and ideal L2 self. There were also significant correlations at $\mathrm{p}<.05$ between changes on teacher's role and desire to learn English, motivational intensity and desire to learn, motivational intensity and ought-to L2 self, and desire to learn and ideal L2 self.

Table 2. Correlation Matrix for TOEIC Scores and Motivational Variables

\begin{tabular}{llllllll}
\hline & TOEIC & Teacher & Efficacy & Motivation & Desire & Ideal & Ought \\
\hline TOEIC & 1.00 & & & & & & \\
Teacher & 0.20 & 1.00 & & & & & \\
Efficacy & 0.09 & 0.01 & 1.00 & & & & \\
Motivation & 0.22 & 0.22 & 0.03 & 1.00 & & & \\
Desire & 0.01 & $\mathbf{. 2 8 4 *}$ & -0.01 & $\mathbf{. 3 0 8} *$ & 1.00 & & \\
Ideal & 0.00 & -0.15 & -0.01 & 0.17 & $\mathbf{. 2 7 0 *}$ & 1.00 & \\
Ought & 0.11 & -0.09 & -0.08 & $\mathbf{. 2 8 1 *}$ & 0.21 & $\mathbf{. 3 3 0 * *}$ & 1.00 \\
\hline
\end{tabular}

** Correlation significant at the 0.01 level (2-tailed).

* Correlation significant at the 0.05 level (2-tailed).

3.3 Research Question Four: Is There a Relevant Correlation between Students' Pre-Departure Motivation and Attitude and Overall Linguistic Gains

To predict gains on the TOEIC scores (from pre- to post-program), multiple regression analysis was employed with the TOEIC gain scores as a dependent variable, and the six pre-departure motivation scores as independent variables (Tables 3). The results of multiple regression analysis indicate that motivation and attitude prior to departure were significant predictors of the TOEIC scores, $F(6,39386.54)=2.59, p<.05, R^{2}=.13$. As shown in 
Table 3, motivation intensity was the only variable that contributed to the prediction of scores in a statistically significant way $(\mathrm{p}<.05)$.

Table 3. Results of Multiple Regression Analysis for TOEIC Gain

\begin{tabular}{|c|c|c|c|c|c|}
\hline & \multicolumn{2}{|c|}{ Unstandardized Coefficients } & \multirow{2}{*}{$\begin{array}{l}\text { Standardized Coefficients } \\
\text { Beta }\end{array}$} & \multirow[t]{2}{*}{$\mathrm{t}$} & \multirow[t]{2}{*}{ Sig. } \\
\hline & $\mathrm{B}$ & Std. Error & & & \\
\hline (Constant) & 58.47 & 98.86 & & 0.59 & 0.56 \\
\hline Teacher & 0.00 & 22.15 & 0.00 & 0.00 & 1.00 \\
\hline Efficacy & 48.78 & 26.81 & 0.25 & 1.82 & 0.07 \\
\hline Motivation & -58.30 & 27.95 & -0.30 & -2.09 & 0.04 \\
\hline Desire & 28.80 & 24.65 & 0.18 & 1.17 & 0.25 \\
\hline Ideal & -2.10 & 21.33 & -0.01 & -0.10 & 0.92 \\
\hline Ought & -12.56 & 20.80 & -0.09 & -0.60 & 0.55 \\
\hline
\end{tabular}

\section{Conclusion and Discussion}

A means comparison of pre and post TOEIC scores showed statistically significant gains for participants in both programs. Given the number of hours of study during the program and direct contact with the target language, this is not surprising. The changes in self-efficacy and motivational intensity are more interesting.

One possible explanation for positive gains on self-efficacy is that the curricula in the SA programs and living in Canada surely gave them experiences that allowed them to see the benefits of both accuracy and fluency in communication as well as giving them a sense of their abilities that they may not have had back on their home campus where so much of their academic life is in their L1.

Explanations for gains in motivational intensity might be because the programs helped to motivate them to study more and take clearer charge of their own learning. What is interesting is that even though their motivational intensity and self-efficacy increased, the role of the teacher in L2 learning did not seem to change much. This negative finding may support studies such as Amuzie et al. (2009). We believe there are some reasons for this. One being the nature of the environment of this study (intact homogenous groups throughout the program) compared with that of Amuzie et al. (non-homogenous groups in more varied study abroad settings). For example, there were a large number of classroom hours designed into the curriculum (as opposed to self-study and research projects) or perhaps the structure of class time in Canada was in many ways similar to that of Japan. Related to this is the possibility is that although self-efficacy and motivation were high, the students may not have had much experience in self-regulatory, non-teacher fronted learning. This supposition would then suggest that more training in self-regulatory strategies is warranted (Pawlak, Czizer, \& Soto, 2020).

Contrary to many studies on changes in self-image, the participants in this study showed no significant change in ideal self and ought-to self. This may imply L2 learning motivation and self-image among the language learners were already positive, and the learners successfully maintained these psychological states throughout their time in the program. This could be supported by the fact that the correlation between the changes in these two variables was significant.

A multiple regression analysis was carried out to uncover specific kinds of motivation and attitudes before departure which might lead to greater linguistic success during the SA programs. The results of the multiple regression analysis supported many previous findings, including that of the pilot study (Mori, 2018). Motivational intensity prior to departure was a significant predictor of TOEIC improvement.

Although there were significant gains on linguistic ability and the variables of self-efficacy and motivational intensity, there were no significant effects for four of the variables (teacher's role, desire to learn English, ideal L2 self, and ought-to L2 self). One explanation for this could be that their desire to learn English was strong to start with and four months was not long enough to affect this variable. This explanation is supported by the findings of Sasaki (2011) and Amuzie et al. (2009). In addition, the survey did not include many items dealing with attitudes towards the target culture. Considering the fact that the participants had very little experience with the target culture prior to departure, this might be an aspect which would see significant change. Future research should include more questionnaire items dealing with attitudes towards the target culture.

Another limitation is that this research was an extension of a pilot study whose purpose was to augment the small sample size and limited scope of the previous study. Although the study achieved its modest aims, several limitations should be mentioned. First, the small sample size and context of the study (both universities were in 
Canada and the curricula had similar goals and aims) limit the generalizability of the findings. Second, a longitudinal design is necessary to establish the robustness of the initial findings. The present study only looked at changes before and immediately after SA. It would be useful to investigate longitudinal changes to self-image and motivation following return to their home campuses and regular courses. Finally, interpretation of the significant changes were the researchers' alone. Adding a follow-up qualitative measure to future research could help reveal how the students interpreted these changes. Other areas for possible consideration for future studies would be attitudinal parameters such as cultural sensitivity and global mindedness. In addition, outcomes of SA programs such as gains in language skills not covered by standard linguistic tests, such as public presentation and communicative ability, should also be considered as variables for future study.

\section{References}

Amuzie, G. L., \& Winke, P. (2009). Changes in language learning beliefs as a result of study abroad. System, 37(3), 366-379. https://doi.org/10.1016/j.system.2009.02.011

Anderson, P. H., Lawton, L., Rexeisen, R., \& Hubbard, C. (2006). Short-term study abroad and intercultural sensitivity: A pilot study. International Journal of Intercultural Relations, 30, 457-469. https://doi.org/10.1016/j.ijintrel.2005.10.004

Barkhuisen, G. (2017). Investigating multilingual identity in study abroad contexts: A short story analysis approach. System, 71, 102-112. https://doi.org/10.1016/j.system.2017.09.014

Dörnyei, Z., \& Ushioda, E. (Eds.). (2009). Motivation, language identity and the L2 self. Bristol: Multilingual Matters. https://doi.org/10.21832/9781847691293

Fryer, M., \& Roger, P. (2018). Transformations in the L2 self: Changing motivation in a study abroad context. System, 78, 159-172. https://doi.org/10.1016/j.system.2018.08.005

Gardner, R. C., \& Lambert, W. E. (1972). Attitudes and motivation in second language learning. Rowley, MA: Newbury House.

Hanada, S. (2019). A quantitative assessment of Japanese students' intercultural competence developed through study abroad programs. Journal of International Students, 9(4), 1015-1037. https://doi.org/10.32674/jis.v9i4.391

Hsieh, C. (2009). L2 learners' self-appraisal of motivational changes over time. Issues in Applied Linguistics, 17(1). https://doi.org/10.5070/L4171005104

JASSO (Japan Student Service Organization). (2018). 2018 Nihonjingakusei ryungakujoukyou chousa kekka [The Results on Status Survey of Japanese Students Studying Abroad 2018].

Martin, J. (2020). Analysis of Short-Term Study Abroad in Japanese Secondary Education. The Journal of Worldwide Education, 13(1), 3-17. https://doi.org/10.37546/JALTSIG.SA.JOWE13.1-1

MEXT (Ministry of Education, Culture, Sports, Science and Technology). (2011). Guroobaru jinzai ikuseisuishinkaigi chuukanmatome [Interim Report on Commission on the Global Human Resources Development].

Miura, T. (2010). A retrospective survey of 12 learning motivational changes. JALT Journal, 32(1), 29-53. https://doi.org/10.37546/JALTJJ32.1-2

Mori, S. (2018). Impact of a Semester Study Abroad Program on Learners' Linguistic Competence and Beliefs: A Pilot Study. Kinki University Center for Liberal Arts and Foreign Language Education Journal. Foreign Language Edition, 9(2), 1-18.

Moritani, H., Manning, C., \& Henneberry, S. (2016). Preliminary findings of L2 motivational changes in a short-term study abroad program. Shimane Journal of Policy Studies, 31, 41-56. Retrieved from https://id.nii.ac.jp/1377/00001508/

Nguyen, A-M, Jefferies, J., \& Rojas, B. (2018). Short term, big impact? Changes in self-efficacy and cultural intelligence, and the adjustment of multicultural and monocultural students abroad. International Journal of Intercultural Relations, 66, 119-129. https://doi.org/10.1016/j.ijintrel.2018.08.001

Nowlan, A. (2020). Japanese university student experiences with internships in Southeast Asia. The Journal of Worldwide Education, 13(2), 4-19. https://doi.org/10.37546/JALTSIG.SA.JOWE13.2-1

Paris, C. M., Nyaupane, G. P., \& Teye, V. (2014). Expectations, outcomes and attitude change of study abroad students. Annals of Tourism Research, 48, 275-277. https://doi.org/10.1016/j.annals.2014.06.007 
Pawlak, M., Csizér, K., \& Soto, A. (2020). Interrelationships of motivation, self-efficacy and self-regulatory strategy use: An investigation into study abroad experiences. System, 93, 102300. https://doi.org/10.1016/j.system.2020.102300

Sasaki, M. (2011). Effects of varying lengths of study-abroad experiences on japanese efl students' 12 writing ability and motivation: A longitudinal study. TESOL Quarterly, 45(1), 81-105. https://doi.org/10.5054/tq.2011.240861

Streitwieser, B., \& Light, G. (2018). Student conceptions of international experience in the study abroad context. Higher Education, 75, 471-487. https://doi.org/10.1007/s10734-017-0150-0

Ueki, M., \& Takeuchi, O. (2015). Study abroad and motivation to learn a second language: Exploring the possibility of the L2 motivational self-system. Language Education \& Technology, 52, 1-25. Retrieved from https://hdl.handle.net/10112/11113

Verela, O. (2017). Learning outcomes of study-abroad programs: A meta-analysis. Academy of Management Learning \& Education, 16(4), 531-561. https://doi.org/10.5465/amle.2015.0250

Watson, J. R., \& Wolfel, R. (2015). The intersection of language and culture in study abroad: Assessment and analysis of study abroad outcomes. Frontiers: The Interdisciplinary Journal of Study Abroad, 25, 57-72. https://doi.org/10.36366/frontiers.v25i1.345

Yang, J.-S., \& Kim, T.-Y. (2011). Sociocultural analysis of second language learner beliefs: A qualitative case study of two study-abroad ESL learners. System: An International Journal of Educational Technology and Applied Linguistics, 39(3), 325-334. https://doi.org/10.1016/j.system.2011.07.005

Yashima, T. (1999). Influence of personality, L2 proficiency, and attitudes on Japanese adolescents' inter-cultural adjustment. JALT Journal, 21, 66-86.

Yashima, T. (2009). International posture and the ideal L2 self in the Japanese EFL Context. In Dörnyei, Z. \& Ushioda, E. (Eds.), Motivation, language identity and the L2 self (pp. 144-163). Clevedon, UK: Multilingual Matters. https://doi.org/10.21832/9781847691293-008

Yashima, T., \& Zenuk-Nishide, L. (2008). The impact of learning contexts on proficiency, attitudes, and L2 communication: Creating an imagined international community. System, 36, 566-585. https://doi.org/10.1016/j.system.2008.03.006

Yashima, T., Zenuk-Nishide, L., \& Shimizu, K. (2004). The influence of attitudes and affect on willingness to communicate and second language communication. Language Learning, 54, 119-152. https://doi.org/10.1016/j.system.2008.03.006

Zaykovskaya, I., Rawal, H., \& De Costa, P. I. (2017). Learner beliefs for successful study abroad experience: A case study. System, 71, 113-121. https://doi.org/10.1016/j.system.2017.09.020

\section{Copyrights}

Copyright for this article is retained by the author(s), with first publication rights granted to the journal.

This is an open-access article distributed under the terms and conditions of the Creative Commons Attribution license (http://creativecommons.org/licenses/by/4.0/). 